\title{
KAOLIN PROCESSING USING FUZZY HYDROCYCLONE CONTROL
}

\author{
M. G. Farghaly \\ Assistant Professor, Mining and Petroleum Engineering Department, \\ Faculty of Engineering, Al-Azhar University, Qena Branch, Qena, Egypt \\ Email: $\underline{m \text { galaly@yahoo.com }}$
}

(Received January 24, 2012 Accepted February 11, 2012)

In many cases, the hydrocyclone control is desirable for efficient separation especially in case of changing feed conditions. Control concept based on exact mathematical models is not satisfactory due to the complexity of the physical process. In this case, fuzzy control is a suitable solution. The data are primarily derived from an optical sensor that monitors the outside view of the free underflow stream (spray angle). A throttling valve, serving as an actuator, is installed around the overflow pipe that regulates the volume split of the cyclone. This work presents a fuzzy hydrocyclone control to stabilize the separation, as a result of varying feed conditions in kaolin processing. The aim is to control the final product size (kaolin) and then to replace the multi-stages hydrocyclones which are currently used with only one stage fuzzy controlled hydrocyclone separation process to produce high quality kaolin in the overflow product even with changing the feed conditions during the separation. The results showed that sharp separations are performed with a spray angle in the range of $25^{\circ}$ to $35^{\circ}$. Therefore, in that application, the control is focused on stabilization of the spray angle. A controlled spray angle of $26^{\circ}$ was found to give optimum results concerning the kaolin quality separated in the overflow. The improved operation characteristics present new options for extensive applications of fuzzy hydrocyclone control.

KEYWORDS: Hydrocyclone, fuzzy control, optical sensing, kaolin processing

\section{INTRODUCTION}

In mineral processing, it is not difficult to design the process control, assuming that the relationships between the input and output parameters can be expressed with an exact mathematical model. Problems arise when facing nonlinear systems, with complex dynamics, such as hydrocyclone separation. There is no mathematical model that sufficiently represents the existing relationships. To overcome these difficulties, Karr and Weck [1] used fuzzy mathematics to produce computer models directly from engineering data acquired from mineral processing systems.

Fuzzy logic does not presuppose an understanding of the physics of the system but utilizes expert experience more than the conventional mathematical approach. Conventional fuzzy control makes use of past experiences and detailed analyses of available data to build fuzzy rules for data analysis. Enhanced developments combine fuzzy logic, genetic algorithms, and neural networks to create expert systems. 
Since fuzzy systems were introduced in mineral processing for improving human-computer interaction, hydrocyclone separation has become the subject of intense investigation [1]. Hydrocyclone separation runs in a turbulent multiphase flow, where particle interaction plays an important role.

Considerable research has been performed [2-5] to develop physically-based process models. Despite remarkable progress, these models cannot deliver the base for hydrocyclone control because of the large number of process parameters, and process instability as well as the influence of solid concentration, particle size, particle shape, and particle agglomeration. The fundamental reason of which these models cannot be explicitly used for developing a process strategy is that they do not capture the dynamics between the input and output variables.

Karr [6-7], Karr, et al. [8], and Weck and Karr [9] presented linguistic computer models tuned with a genetic algorithm, which is employed to simultaneously select linguistic rules and tune fuzzy membership functions. Fung, et al. [10-11], and Wong et al. [12] developed a self-generating fuzzy rule technique to extract fuzzy rules directly from input-output data. Wong et al. [13] constructed a hybrid fuzzy system, which can be used for hydrocyclone parameter identification and to estimate the cut size of the hydrocyclone. It used mimetic algorithms to optimize the fuzzy parameters of the apparatus.

This paper presents a fuzzy hydrocyclone control to stabilize the separation, as a result of varying feed conditions in kaolin processing. The aim is to replace the multistages hydrocyclones which are currently used with only one stage fuzzy controlled hydrocyclone separation process to produce high quality kaolin in the overflow product even with changing the feed conditions during the separation (changing the feed solid content and - or feed particle size)

\section{STATE OF THE HYDROCYCLONE CONTROL}

The hydrocyclone classifier is considered the favored classifying device in mineral processing to obtain cut sizes between 10 and $100 \mu \mathrm{m}$. The advantages of hydrocyclone include its simplicity, ease of operation, high volumetric throughput and relatively low capital, operating and maintenance costs. Uniform feed properties are a requisite for good separation efficiency by hydrocyclones, since varying feed conditions lead to considerable fluctuations of cut size and separation sharpness [5].

Significant effort has recently been undertaken to compensate for above difficulties by hydrocyclone control. Various types of equipment have been employed to control the volume split of the hydrocyclone [14]. These devices include collapsible tubing made of resilient material, flap valves and counterbalanced piping applied to the apex of the hydrocyclone. The use of such devices at the underflow has resulted in increasing maintenance and choking or plugging. Alternatively, one may control separation by manipulating the feed side. The feed solid content is controlled by water addition [15]. This leads to an increased hydrocyclone feed rate. Consequently, water addition must be combined with speed control of the feeding pump and/or the automatic switch of additional hydrocyclones. This method is often applied to hydrocyclones in closed circuit grinding [16]. However, the varying feed rate is a disadvantage in these downstream processes. 
A control proposed by Neesse et al. [17], which performed at the overflow side, presents the advantages of better accessibility compared with the underflow and lower wear due to the finer particles. Furthermore, a hydrocyclone group can be controlled by installing only one valve in the collecting pipe of overflow. Using this system, the hydrocyclone operation can be stabilized and even optimized to regulate the volume split and feed pump speed.

\section{FUZZY CONCEPT}

\subsection{Operator experience}

The new control concept is based on a conventional fuzzy logic data analysis and makes use of detailed analysis of measured hydrocyclone data and the operator's experience to build fuzzy rules. Fuzzy logic is focused on the behavior of hydrocyclone underflow. The experienced operator understands that the features and flow characteristics of the free underflow stream are sensitive indicators of the operational state of the apparatus.

Depending on feed conditions, various shapes of the free underflow stream can be observed [18-20]. In dilute flow separation with a typical spray discharge, a widening air core spreading to the underflow can be observed. The resultant separation may result in high solid recovery of the underflow, which may be regarded an advantage, but relatively low solid concentrations may result in more fine particles which being misdirected to the underflow.

In dense flow separation (high percentage feed solids content), sediment may be held up dynamically in the conical part of the hydrocyclone. In this case, the coarse particles may move towards the overflow, thereby reducing solid recovery to the underflow. Also, the air core may not extend over the complete hydrocyclone length, and may oscillate intensively or be otherwise unstable.

The underflow shape is determined by suspension rheology. At high dynamic viscosity, the free vortex collapses and the underflow discharge may be assumed a rope shape. This behavior is influenced by the particle size and shape distribution, as well as, by surface conditions and the swelling properties of the solid phase. For a given solid phase, the dynamic viscosity is dependent upon the solid content. Rope discharge is characterized by high solids content with fewer fine particles. Although this is not often the case, this situation can be considered advantageous [19].

In the transition state, a quick change between spray and rope discharge occurs. A change in the underflow behavior, specifically the change of the spray angle, indicates to the changing process conditions. In reality, the shape and movement of the underflow is more complex, resulting in unsteady effects. Fluctuations of the spray angle, eccentricities of the stream, and quick changes in the rope/spray discharge are observed which cannot be explained theoretically. The intense unsteady stream indicates to the transition state of the rope/spray discharge. Thus, this is considered a typical situation to design the process control using fuzzy sets with fuzzy rules [20].

\section{FUZZY CONTROLLED HYDROCYCLONE TEST RIG}

The new technological concept involves the installation of controlled valve around the overflow pipe together with an infra red sensor above the underflow opening. The test rig of the fuzzy automatic control hydrocyclone is shown in Fig. 1. 
It consists of a $150 \mathrm{~mm}$ hydrocyclone with $0.9 \mathrm{~m}^{3}$ capacity sump in which the suspension is prepared. The sump contains a mechanical stirrer driven by an electrical motor for suspension agitation process before feeding into the hydrocyclone. This sump is connected to a sand pump driven by an electrical motor of $5.5 \mathrm{~kW}$. The pump delivered the suspension from the sump and feeds it under pressure to the hydrocyclone through the feed inlet pipe.

A throttling valve is mounted around the overflow pipe and a sensor for detecting the shape of the underflow discharge is arranged beneath the apex. Both overflow and underflow streams are discharged again in the sump making a closed circuit flow. The feed and the overflow pipes contain sampling valves through which current samples can be taken for the essential measurements. The underflow samples can be taken directly from the downward stream through the apex with special containers. The sensor signals together with values of the power input of the feed pump and the pressure in the feed and in the overflow are transmitted through special connections to the computer unit which operates the fuzzy automatic control program. Fig. 2 shows in details the installation of the sensor and the throttling valve of the current hydrocyclone test rig.

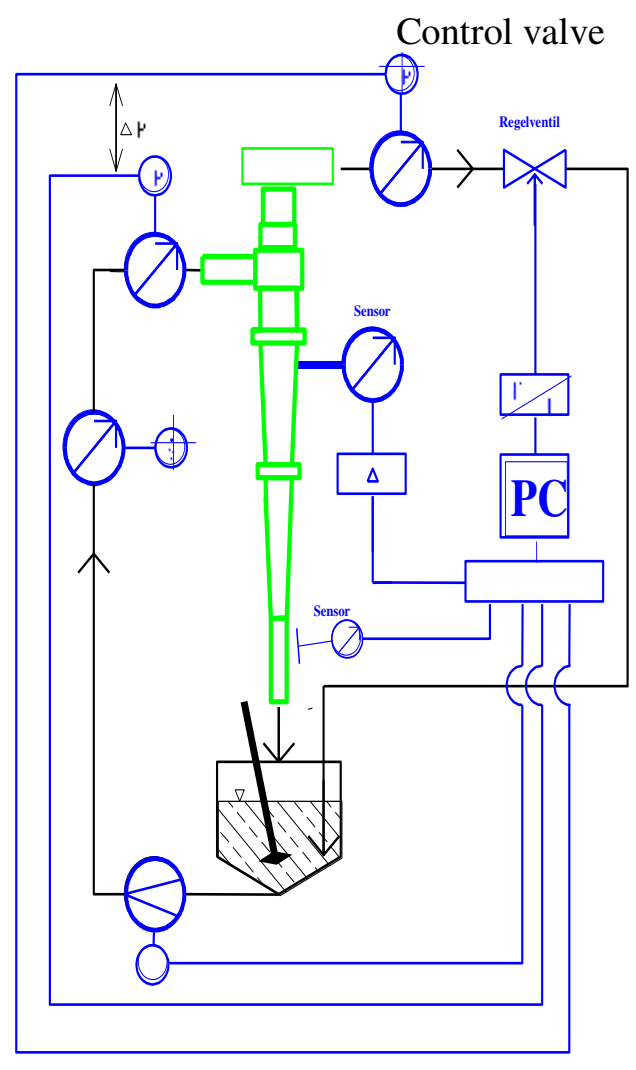

Fig. 1a: Flow chart of semi-technical single controlled hydrocyclone plant

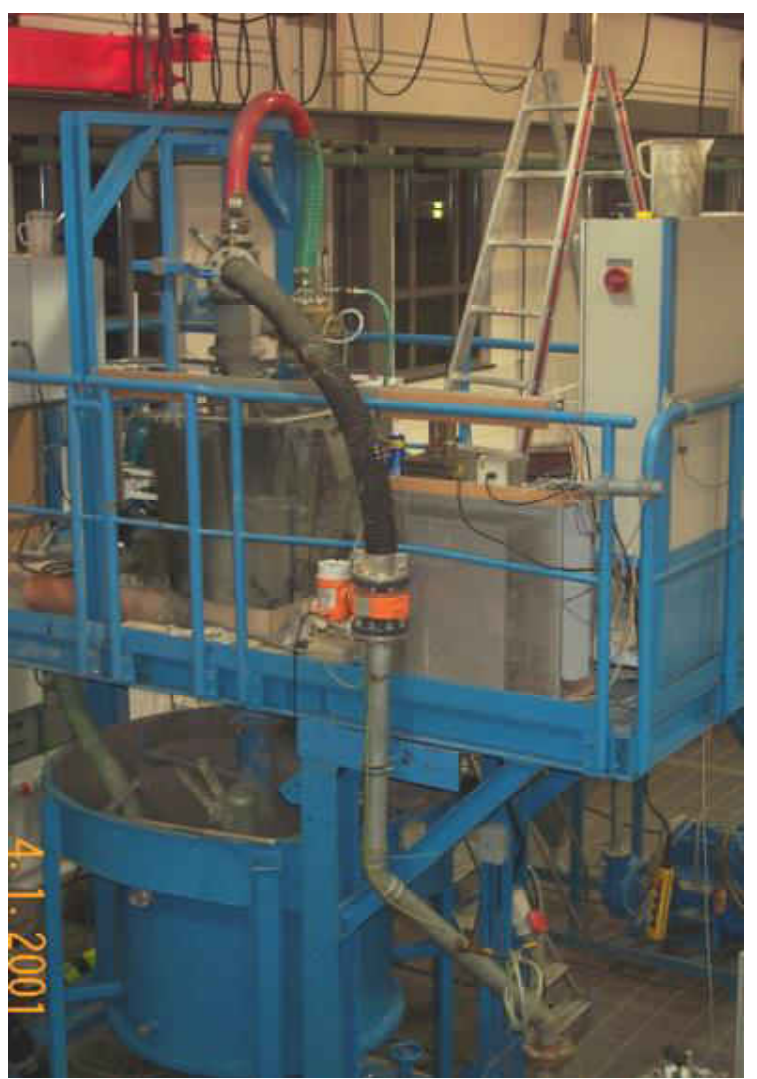

Fig. 1b: Photo of semi-technical controlled hydrocyclone plant 

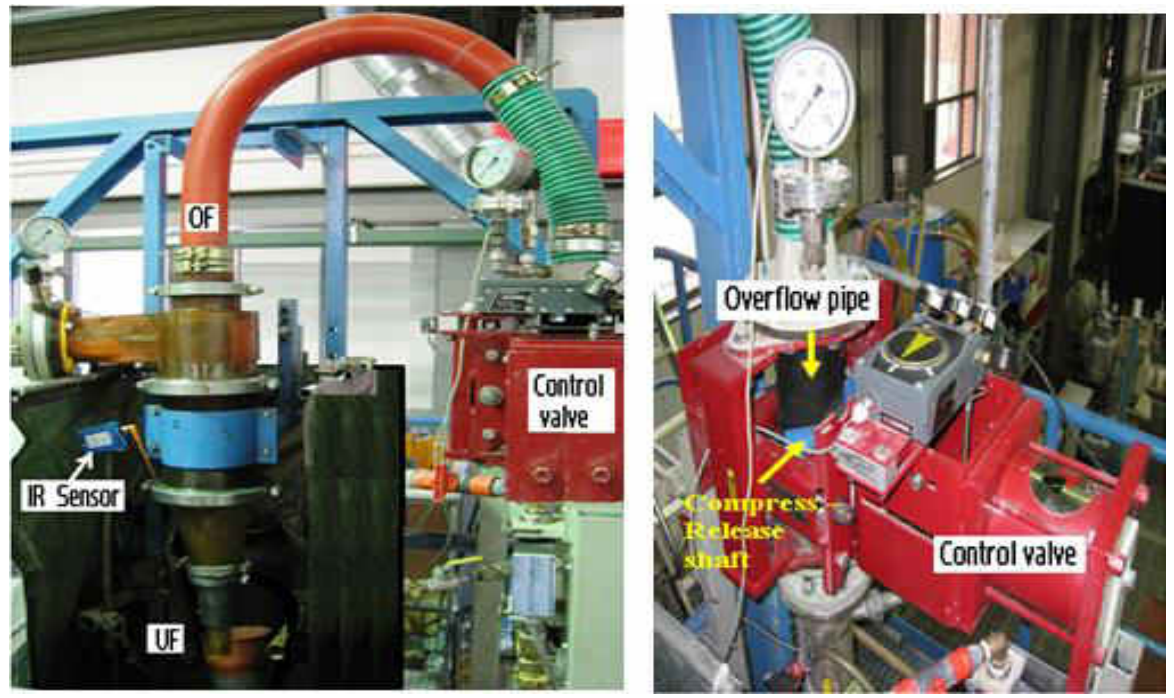

Fig. 2: A $150 \mathrm{~mm}$ Hydrocyclone with IR sensor and a control valve around the overflow pipe

\subsection{Data Base and Fuzzy Control}

Figure 3 depicts the generic structure of the fuzzy hydrocyclone control. A special sensor monitoring the underflow stream delivers the database of the control, which contains definitions of the fuzzy control rules, linguistic labels, and the membership functions of the fuzzy sets.

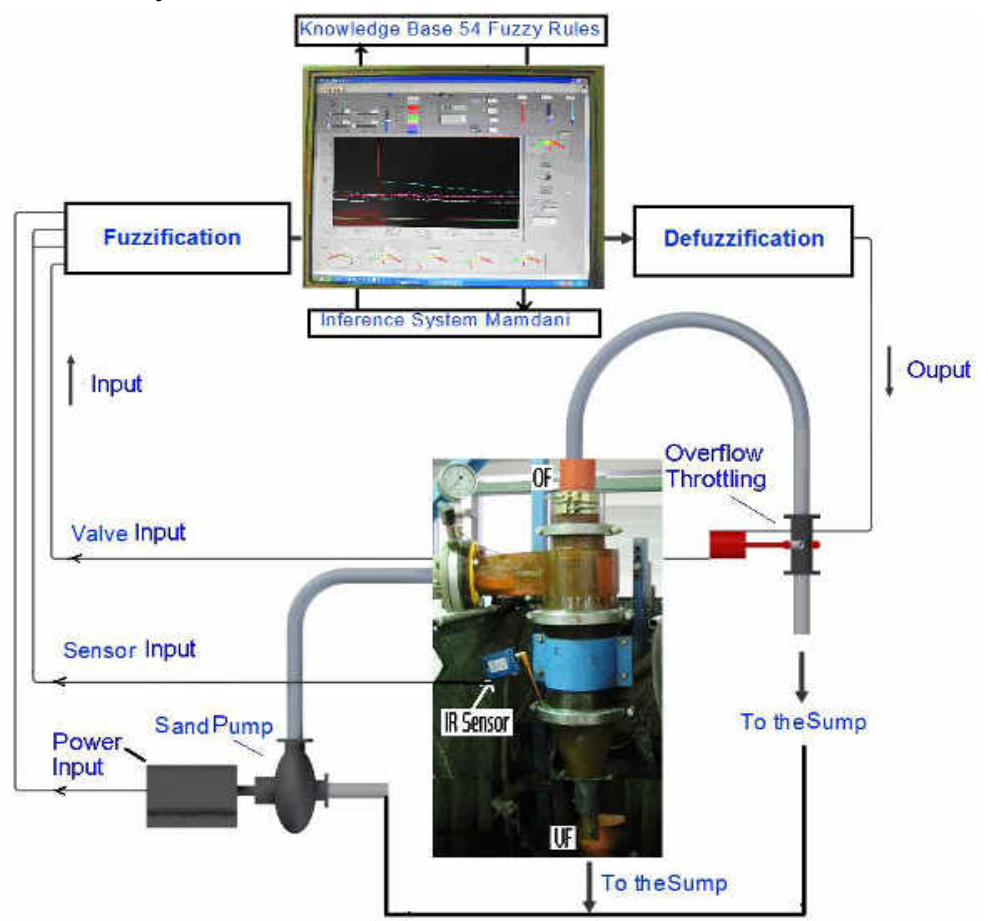

Fig. 3: The generic structure of the fuzzy hydrocyclone control 
Many monitoring methods of the underflow shape were investigated by many authors [19-22]. Recently, better results were obtained using IR (Infrared) measurements as reported by Neesse, et al. [23]. The IR sensor is an indirect, noninvasive method. The sensor may be installed about one meter away from the splashing underflow. Signals from the infrared sensor which indicate the shape and time behaviour of the underflow stream are transmitted to the fuzzification interface and are completed by the pump power input and control valve opening. Hence, set of four state variables are considered for the fuzzy logic.

Based on the knowledge base comprised of information derived from process monitoring in the form of 54 linguistic control rules, a fuzzification interface with the ability to transform crisp data into fuzzy sets was developed. The inference system, in addition to the knowledge base, makes inferences by means of a reasoning method. Finally, the defuzzification interface translates the fuzzy control action into real control action and hence regulates the volume split of the hydrocyclone.

Control action is performed by a valve in the hydrocyclone overflow that regulates the volume split and the solid discharge in the underflow. Each control interval is about $0.3 \mathrm{sec}$. The control mechanism actuated by stepwise overflow throttling intensifies the pressure inside the hydrocyclone. Accordingly, the underflow discharge, together with the spray angle, increase until a critical point is reached where throttling is decreased to a lower value. Afterwards, a new control interval begins. Fuzzy logic enables stabilization of separation at the unstable point of transition rope/spray underflow discharge.

\section{KAOLIN PROCESSING USING CONVENTIONAL HYDROCYCLONE SEPARATION}

The clay mineral kaolin is one of the most important and useful industrial minerals in the world. The major uses of kaolin are in the paper, ceramic, paint, plastic, rubber, and cracking catalyst industries. Kaolin should be cleaned prior to being processed. Kaolin is washed in hydrocyclone which is considered the most promising method at the present time, to separate it from contaminants such as quartz and undecomposed feldspars by dispersion of the mined ore and then classification by multistage hydrocyclone plants as shown in Fig. 4.

As illustrated in Fig. 4 Kaolin reports to the overflow is then reprocessed in other smaller cyclones. Due to inefficiency associated to hydrocyclone, most plants are not able to produce clean kaolin even after the 4th or 5th hydrocyclone stage. This results in producing a middling stream (product) which is commonly disposed into the quarry. This middling stream can be treated via flotation but due to the environmental impact of using cationic collectors (amines), the flotation plant has to be operated in a wet grinding closed circuit. Another disadvantage is that in the classification of fine particle products like kaolin using hydrocyclones, the overflow delivers the final product, and therefore, size distribution must be kept constant for clean kaolin.

In the conventional separation methods, the overflow quality changes if the feed solid content and feed size distribution are changed during the separation. This causes inferior separation and coarser cut size (misplaced sand particles separated within the overflow product, kaolin. Accordingly, processing techniques should be improved and new equipment should be introduced to obtain kaolin product with the required characteristics. 


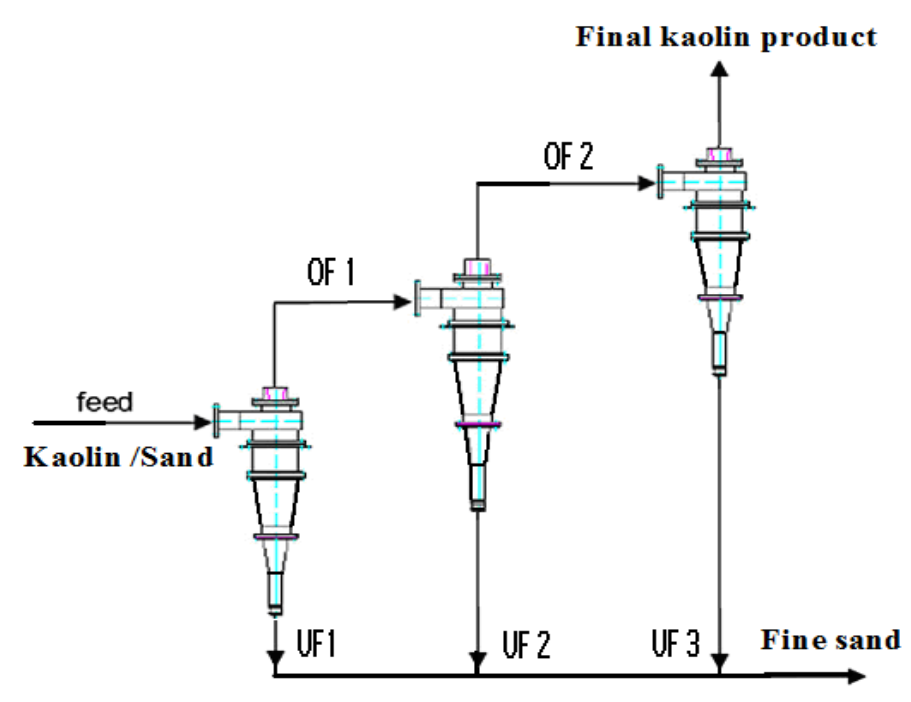

Fig. 4: Kaolin processing using multistage hydrocyclone separation

\section{KAOLIN PROCESSING USING FUZZY CONTROLLED HYDROCYCLONE}

The first applications of fuzzy hydrocyclone control have recently been reported. The control concept was initially applied in bentonite regeneration for tunnel driving [21]. Another application of the fuzzy hydrocyclone control was successfully applied in sand processing for the thickening of fine sand $<150 \mu \mathrm{m}$ with residual moistures $<20 \%$, which is necessary for the transport and storage of the dewatered sand. This option was difficult to be achieved with the conventional methods [23].

In this research, many experiments have been carried out at different feed solid content and different spray angles of the underflow discharge. These experiments were executed in two procedures, the normal separation without applying the fuzzy control system and the other with applying the control concept to compare the results in both cases.

The results showed that sharp separations are obtained within a spray angle of about $25^{\circ}-35^{\circ}$. It was found that at higher feed solid content, the spray angle tended to have lower values of $<20^{\circ}$. Afterwards, the spray changed to rope discharge, and the overflow becomes markedly coarser. Therefore, in that application, the control is focused on stabilization of the spray angle.

Figures 5 through 8 revealed the classification results of sand/kaolin mixture in a $150 \mathrm{~mm}$ hydrocyclone with and without fuzzy control at different spray angles. 


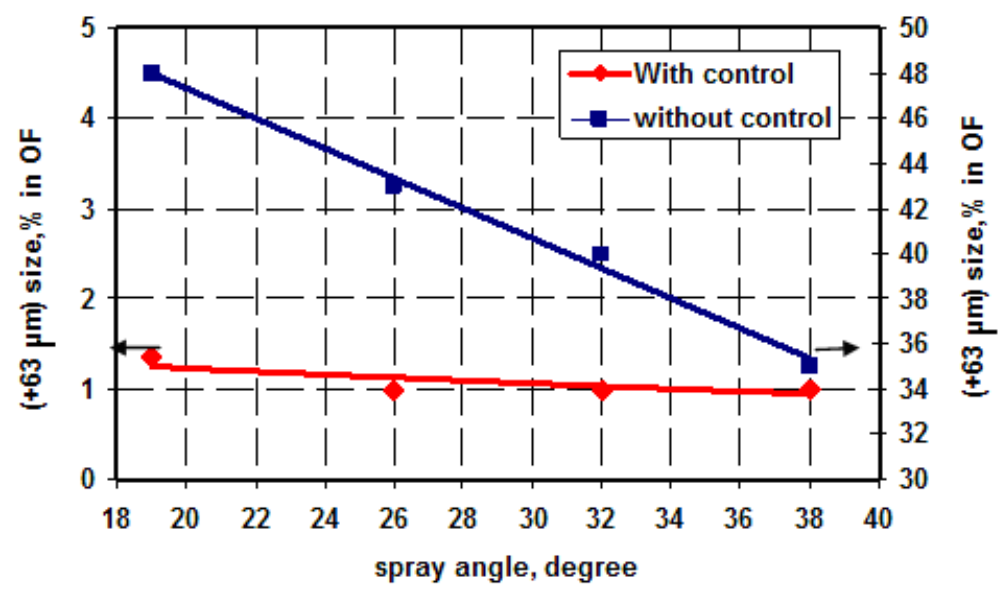

Fig. 5: Effect of spray angle value on the percentage of $+63 \mu \mathrm{m}$ separated in the overflow

Figure 5 showed that the increase in spray angle of the underflow discharge results in a decrease in the percentage of the misplaced coarse size $+63 \mu \mathrm{m}$ (sand) separated in the overflow product (kaolin) in both cases (with and without fuzzy control). This means that higher kaolin quality should be expected at higher values of spray angles. On the other side, it can be shown clearly that for the same spray angles values there is a mark difference between the results obtained with and without applying the fuzzy control system. The percentage of the size $+63 \mu \mathrm{m}$ misplaced in the overflow product was much lower when the control system was applied. This assured the successful effect of the volume split control action. The same trend was observed also for the other examined effects of the control system on the different characteristics of overflow and underflow streams as illustrated in Figures 6 though 8.

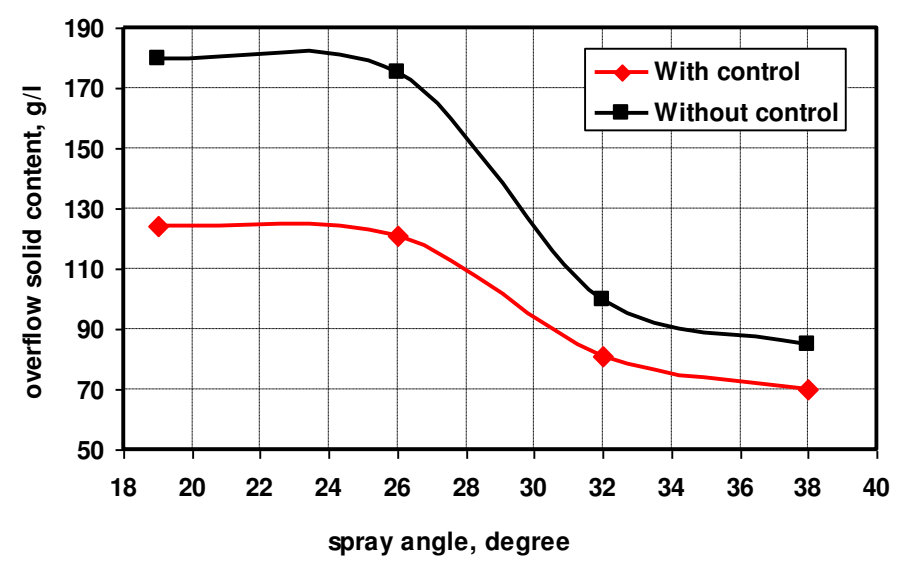

Fig. 6: Effect of spray angle on the overflow solid content

Figure 6 shows that the overflow solid content decreases gradually by increasing the spray angle values in both cases (with and without fuzzy control). This means that more solids are separated through the underflow stream at higher spray angles values. The results revealed also that the overflow solid content is much lower 
in case of applying the fuzzy control at the same spray angle values. This strongly assured the effect of the control system in maintaining a high quality kaolin product by controlling the particle size of the overflow (preventing coarse particles from going to overflow).

Figure 7 illustrated the effect of increasing the spray angle values on the underflow solid content. From this figure, it can be seen that the solid content of the underflow decreased with small values in both cases (with and without fuzzy control). This may be due to the increase of water amounts go to the underflow in case of spray discharge with high spray angle values.

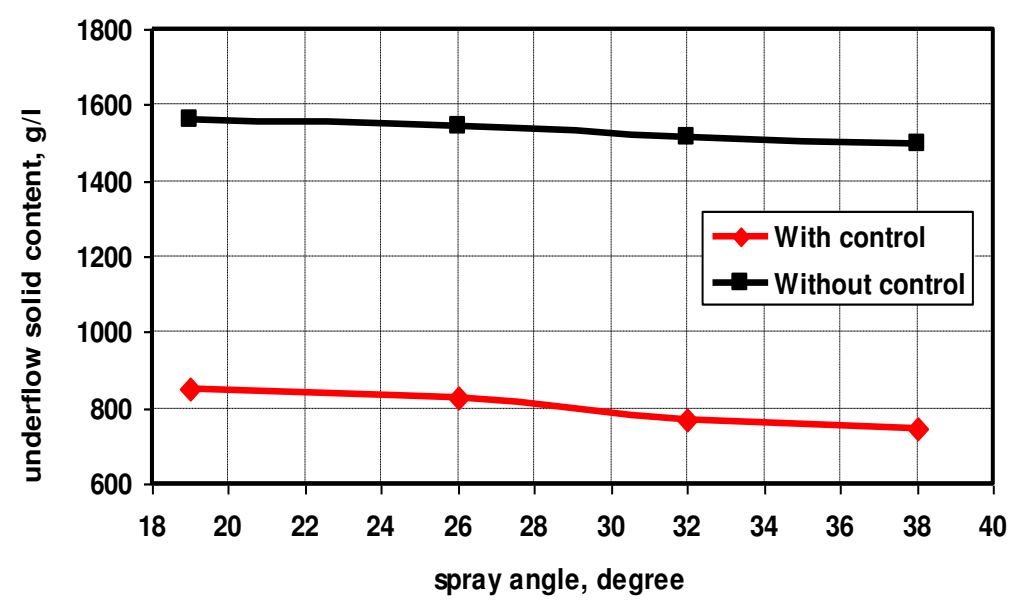

Fig. 7: Effect of spray angle on the underflow solid content

Figure 8 revealed the effect of increasing the spray angle values on the underflow solids flow rate. From this figure, it can be seen that the underflow solid flow rate increased with small values in case of fuzzy control but it greatly increased in case of normal separation without fuzzy control. This may be attributed to the effect of the control which adjusted the flow rate according to the fuzzy rules in relation to the spray angle value.

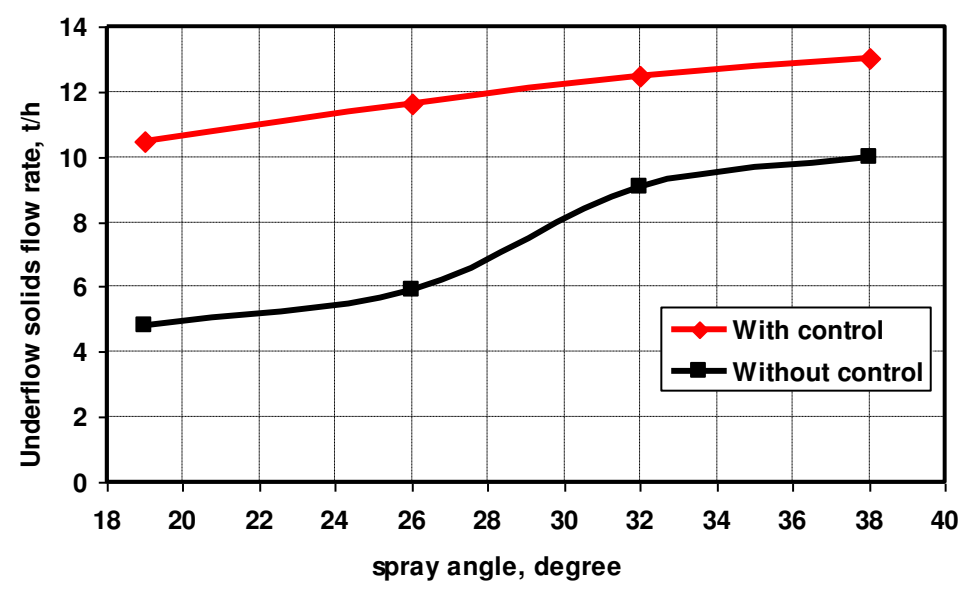

Fig. 8: Effect of spray angle on the underflow solids flow rate 
From the above discussed results, it can be illustrated that the fuzzy control system has a marked effect on kaolin processing. The above results also assured the dependency of the control effect on the spray angle value of the underflow discharge. A spray angle of about $26^{\circ}$ was found to be an optimum value at which the control effect was stabilized and an enhanced separation was obtained with high quality kaolin product in the overflow. Figure 9 shows the effect of using the fuzzy control system on separation process of kaolin at a spray angle of $26^{\circ}$ with different feed solid contents. Fig. 9a observed the solid flow rates to the underflow. Without control, the underflow was changed at about $170 \mathrm{~g} / \mathrm{L}$ feed solid content to rope discharge, where the maximum solid discharge capacity was reached. At higher feed solid content, the underflow solid remained almost stable because the coarse particles were more misplaced to the overflow. The curve "with control" in Fig. 9a indicated that a maximum discharge capacity did not occur. At higher solid content, the controlled overflow was increasingly throttled, which results in an intensified underflow stream due to the higher pressure in the apex. The underflow solid content in Fig. 9b increased without control up to a maximum value of about $1500 \mathrm{~g} / \mathrm{l}$ for rope discharge. As expected, the underflow solid content "with control" was lower. A maximum value of about $900 \mathrm{~g} / \mathrm{l}$ was observed at a feed solid content of about $270 \mathrm{~g} / \mathrm{L}$. Figures $9 \mathrm{c}$ and $9 \mathrm{~d}$ represented the overflow characteristics. From Fig. 9c, it can be clearly seen that the overflow solid content for the controlled cyclone remained almost constant, even at a high feed solids content of $320 \mathrm{~g} / \mathrm{L}$. Without control, the overflow solid content was twice at the same high feed solid content. Fig. 9d indicated that higher overflow solid content was attributed to misplaced coarse particles of $+63 \mu \mathrm{m}$. With control, the percentage of misplaced coarse particles can be stabilized at a value of about $1 \%$. Thus, fuzzy control guarantees the quality of the final overflow product (kaolin) with changing the feed conditions.

\section{CONCLUSIONS}

The hydrocyclone is a very successful separation device. However, in this apparatus the separation results change with the feed conditions. As a result, every cyclone control should be designed to stabilize cut size and separation sharpness for varying feed solid content and feed size distribution. Despite its simple construction, the "inner live" of the cyclone is complicated, such that control based on exact mathematical models is not successful. Here, fuzzy logic may be the best way to find the essential control point in the process and to develop an effective and simple control concept.

The database primarily provides the outside view of the free underflow stream that delivers the precondition for regulating the volume split of the suspension discharge. The technical design considers the demand that the simplicity of the cyclone design should not be altered by complicated control devices. The sensor for monitoring the underflow shape is located some distance from the apparatus and the control valve, which functions as an activator, is located behind the apparatus in the overflow pipe. 

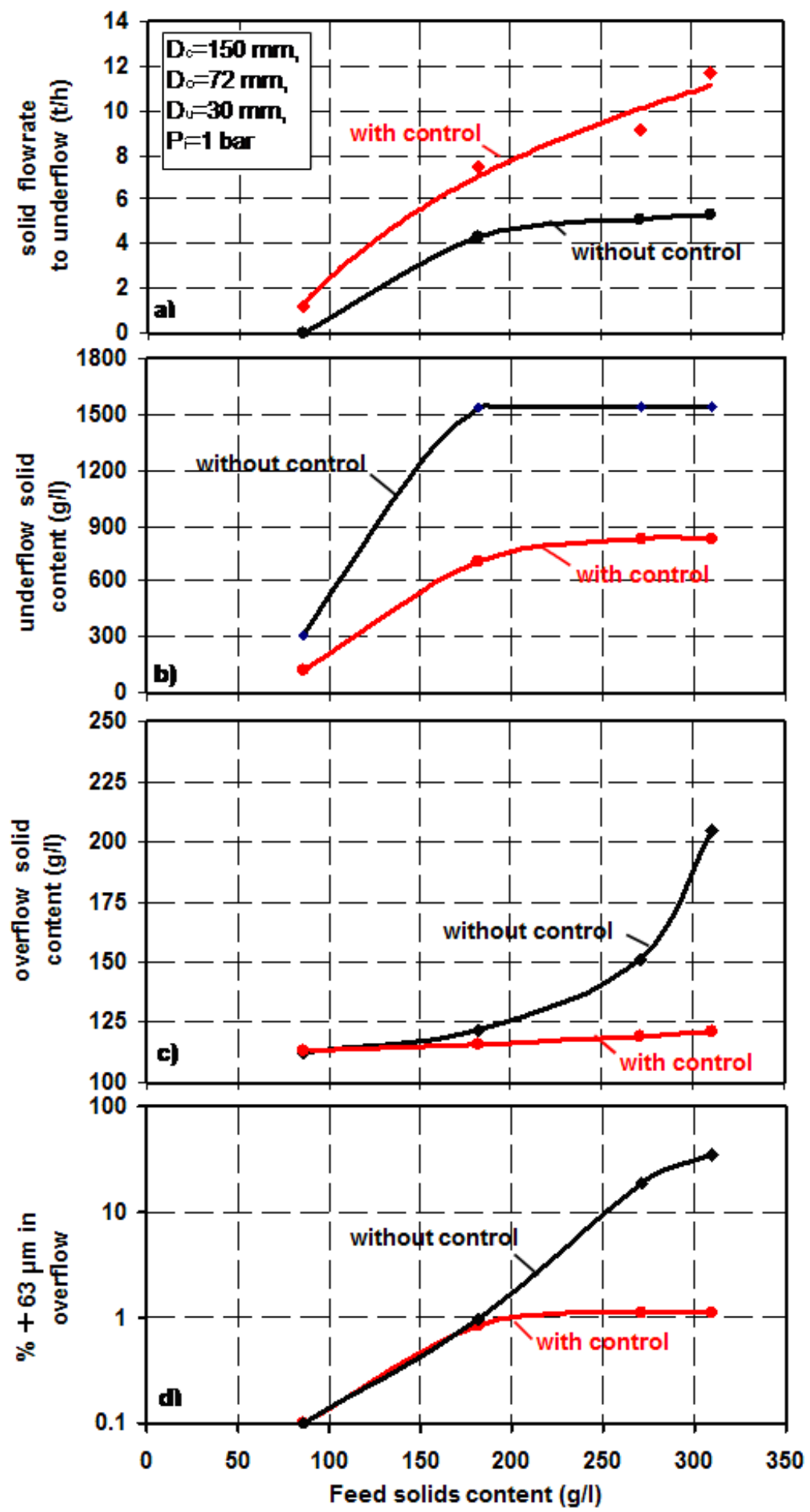

Fig. 9: Classification of sand/kaolin mixture with and without control at spray angle of $26^{\circ}$ 
The applications discussed above demonstrate that this control mechanism guarantees process stabilization for a wide range of feed variations. In addition, this control improves the technological characteristics of the apparatus and enables new cyclone applications. Examples of possible new applications include the dewatering of fine sand and saving a second hydrocyclone stage in the separation plant of tunnel driving. The main reasons for the improvements by fuzzy control are the increased discharge capacity of the underflow nozzle and the option to operate the cyclone at the spray/rope transition point, which in many cases represents the optimal separation point.

Because the control system hardware (optical sensor and throttling valve) is relatively inexpensive and may be retroactively installed, fuzzy volume split control for hydrocyclone could be extensively applied.

Finally, for special cases the cut size of the hydrocyclone can be modified by changing the spray angle, which is easily carried out by sensor adjusting. Thus, fuzzy control supports hydrocyclone separation in a wide range of technological applications.

\section{REFERENCES}

[1] Karr, C. L., and Weck, B., 1996. Computer modeling of mineral processing equipment using fuzzy mathematics. Minerals Engineering, Vol. 9, No. 2, pp. 183-194.

[2] Schubert, H., and Neesse, T., 1980. A hydrocyclone separation model in consideration of the turbulent multi-phase flow. Proc. 1st Int. Conf. Hydrocyclones, Cambridge, British Hydromechanics Research Association, Cranfield, Pap. 3, pp. 23-36.

[3] Neesse, T., Dueck, J., and Minkov, L.L., 2004. Separation of finest particles in hydrocyclones. Minerals Engineering, Vol. 17, pp. 689-696.

[4] Dyakowski, T., and Williams, R. A., 1993. Modeling turbulent flow within a small diameter hydrocyclone, Chemical Engineering Science, Vol. 48, No. 6, pp. 1143-1152.

[5] Narasimha, M., Sripriya, R., and Banerjee, P. K., 2005. CFD modeling of hydrocyclone-prediction of cut size. International Journal of Mineral Processing, 75, 53-68.

[6] Karr, C. L., 1987. Analysis and optimization of air-sparged hydrocyclone using genetic algorithms, U.S. Bureau of Mines.

[7] Karr, C. L., 1991. Air-injected hydrocyclone optimization via genetic algorithm. In: the genetic algorithms handbook, L. D. Davis (Ed.), Van Nostrand Reinhold Company, New York, pp. 222-236.

[8] Karr, C. L., Stanley, D. A., and Mc Whorter, B., 2000. Optimization of hydrocyclone operation using a geno-fuzzy algorithm. Computer Methods in Applied Mechanics and Engineering, 186, pp. 517-530.

[9] Weck, B., and Karr, C. L., 1998. Hydrocyclone model using genetic programming. In: Industrial applications of genetic algorithms, Karr C. L. and Freemann L. M. (Eds.),Boca Raton, FL: CRC Press, pp. 285-298.

[10] Fung, C. C., Wong, KW, and Wong, P. M., 1997. A self-generating fuzzy rules interference systems for petrophysical properties prediction, Proceedings of IEEE International Conference on Intelligent Processing Systems, pp. 205-208. 
[11] Fung, C. C., Wong, K. W., and Eren, H, 1998. Developing a generalised neuralfuzzy hydrocyclone model for particle separation. Proceedings of IEEE Instrumentation and Measurement Technology Conference, pp. 334-337.

[12] Wong, K. W., Fung, C. C., Eren, H., and Gedeon, T., 2003. Fuzzy rule interpolation for multidimensional input spaces in determining $\mathrm{d}_{50 \mathrm{c}}$ of hydrocyclones. IEEE Transactions on Instrumentation \& Measurement, 52(6), pp. 1865-1869.

[13] Wong, K. W., Ong, Y. S., Eren, H., and Fung, C. C., 2004. Machine learning and cybernetics. Proceedings of 2004 International Conference on Mathematical Modeling ,Volume 7, Issue, 26-29, Aug., 2004, pp. 4188-4193.

[14] Martin, D.L., 1978. Hydrocyclone underflow density control. US Patent 4203834.

[15] Walters, L., Placha, D., 2002. System and method for controlling water-only cyclones. US Patent 5248442.

[16] Rajamani, R. K., and Herbst, J. A., 1991. Optimal control of a ball mill grinding circuit, grinding circuit modelling and dynamic simulation. Chemical Engineering Science 46 (3), pp. 861-870.

[17] Neesse, T., Schneider, M., Dueck, J., Donhauser, F., Regler, J., and Tiefel, H., 2003a. Computer controlled hydrocyclone battery with maximum solids recovery. Proceedings XXII International Mineral Processing Congress, Cape Town, South Africa, pp. 1552-1560.

[18] Neesse, T., Schneider, M., Dueck, J., Golyk, V., Buntenbach, S. and Tiefel, H., 2004a. Hydrocyclone operation at the transition point rope/spray Discharge. Minerals Engineering 17, pp. 733-737.

[19] Neesse, T., Golyk, V., Kaniut, P. and Reinsch, V., 2004b. Hydrocyclone control in grinding circuits. Minerals Engineering 17, pp. 1237-1240.

[20] Neesse, T., Schneider, M., Golyk, V. and Tiefel, H., 2004c. Measuring the operating state of the hydrocyclone. Minerals Engineering, Vol. 17, pp. 733-737.

[21] Neesse, T., Schneider, M., Regler, H., Donhauser, F. and Tiefel, H., $2003 \mathrm{~b}$. Technical processes in the regeneration of bentonite suspensions for hydro-shield drives. Tunnel 3, pp. 29-35.

[22] Neesse, T., Tiefel, H. and Kaniut, P., 2007. Volume split control of a hydrocyclone group. Minerals Engineering 20, pp. 355-360.

[23] Neesse T., Farghaly, M., Hararah M., Proellss, G., Rubarth, W., Kaniut, P., 2011 .Higher classification efficiency by hydrocyclone control, Canadian Institute of Mining, Metallurgy, and Petroleum (CIM) Journal, Vol. 2, No. 2, pp. 85-91. 


\section{استخدام الأكاء المشوش في الهيدروسيكلون لمعالجة الكاولين}

يعتبر استخدام وسائل التحكم الآلي في جهاز الهيدروسيكلون مرغوبا في كثير من التطبيقات و ذلك للحصول

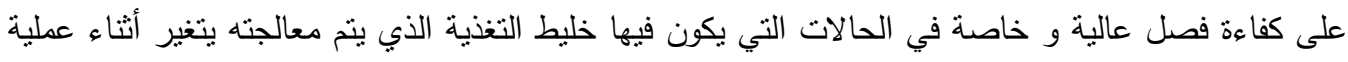

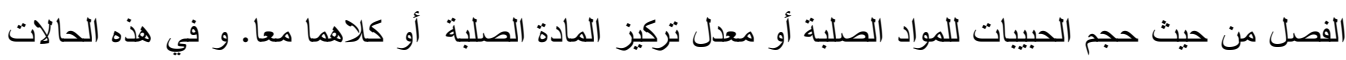
يكون مفهوم عملية النحكم التي تعتمد على النماذج الرياضية التقليدية غير كافي نظرا لطبيعة عملية الفصل المعقدة والتي تحدث داخل الهيدروسيكلون.

و في هذه الحالة فان التحكم باستخدام الذكاء المشوش (Fuzzy Control) يمكن أن يكون حلا مناسبا حيث

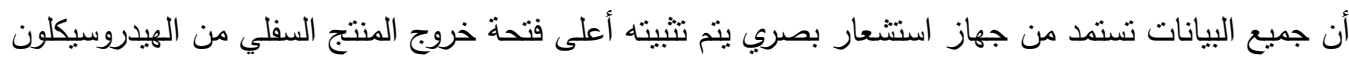

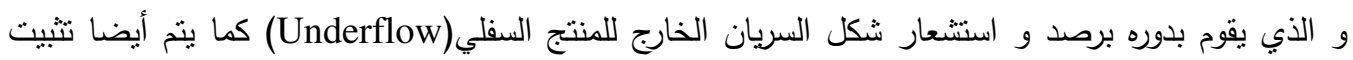

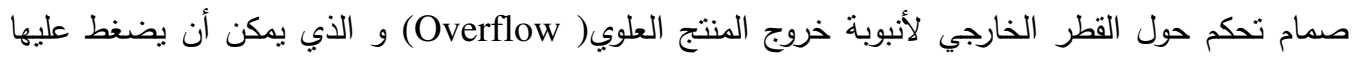
للاخل أو يتحرك بعيدا عنها للخارج. و في هذا البحث يتم تقديم أسلوب جديد للتحكم في جهاز الهيدروسيكلون باستخدام الذكاء المشوش Fuzzy)

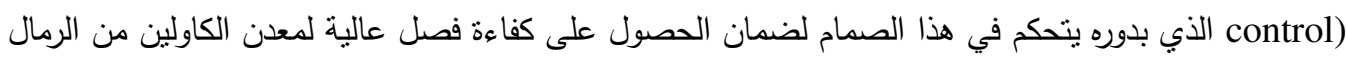
الدصاحبة له في خليط التغذية بالهيدروسيكلون و ذلك بالتحكم في حجم حبيبات المنتج النهائي للكاولين المفصول

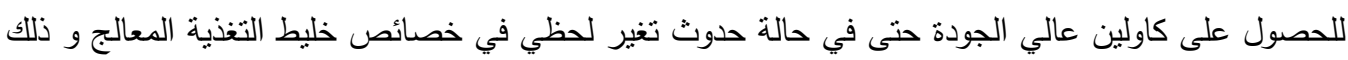

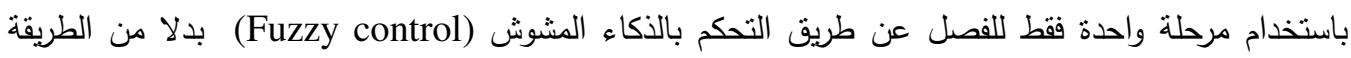

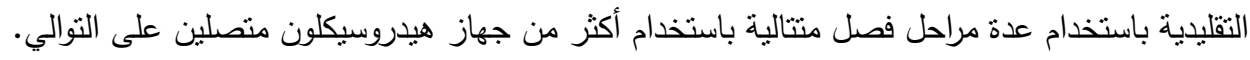

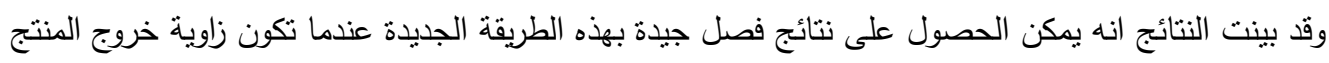

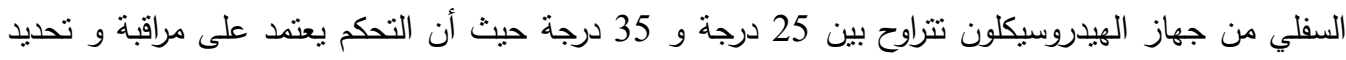

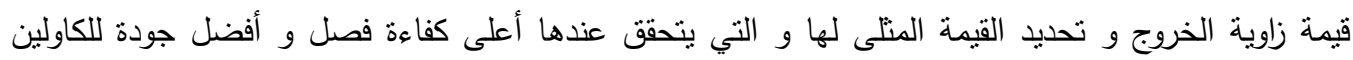

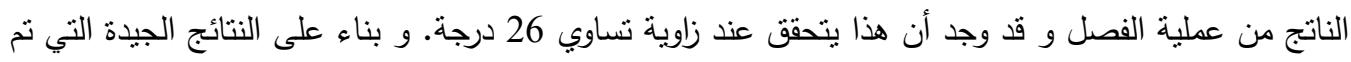

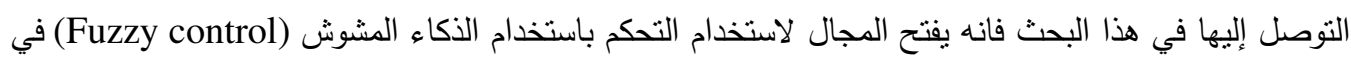
نطبيقات أخرى كثيرة في مجال تركيز و معالجة الخامات. 